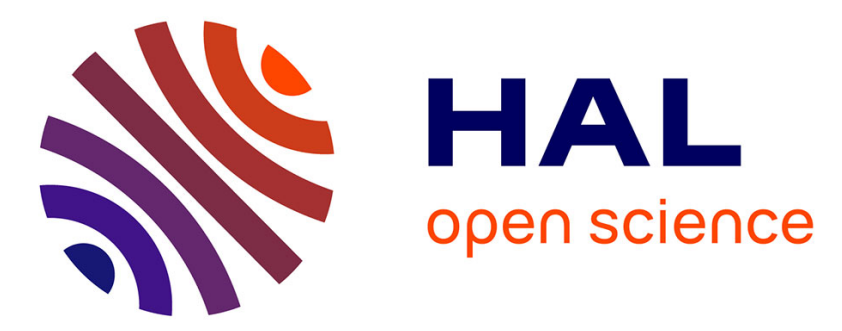

\title{
Feeling better: tactile verbs speed up tactile detection
}

Véronique Boulenger, Marie Martel, Cécile Bouvet, Livio Finos, Jennifer

Krzonowski, Alessandro Farne, Alice Catherine Roy

\section{To cite this version:}

Véronique Boulenger, Marie Martel, Cécile Bouvet, Livio Finos, Jennifer Krzonowski, et al.. Feeling better: tactile verbs speed up tactile detection. Brain and Cognition, 2020. hal-02570439

\section{HAL Id: hal-02570439 \\ https://hal.science/hal-02570439}

Submitted on 12 May 2020

HAL is a multi-disciplinary open access archive for the deposit and dissemination of scientific research documents, whether they are published or not. The documents may come from teaching and research institutions in France or abroad, or from public or private research centers.
L'archive ouverte pluridisciplinaire HAL, est destinée au dépôt et à la diffusion de documents scientifiques de niveau recherche, publiés ou non, émanant des établissements d'enseignement et de recherche français ou étrangers, des laboratoires publics ou privés. 


\section{Feeling better: tactile verbs speed up tactile detection}

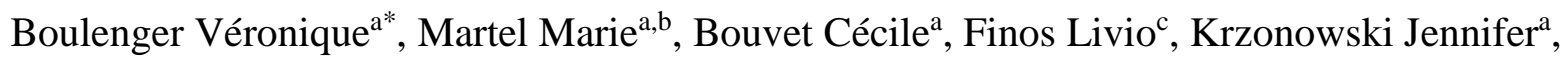
Farnè Alessandro $^{\text {d,e }} \&$ Roy Alice Catherine ${ }^{\mathrm{a}}$

${ }^{\text {a }}$ Laboratory Dynamique du Langage CNRS/Lyon 2 University UMR5596, Maisons des Sciences de l'Homme, 14 avenue Berthelot, 69007 Lyon, France

${ }^{\mathrm{b}}$ Department of Psychology, Royal Holloway, University of London, Egham TW20 0EY, London, England

${ }^{\mathrm{c}}$ Department of Statistical Sciences, University of Padova, Via Battisti, 241 - 35121, Padova, Italy

${ }^{\mathrm{d}}$ Integrative Multisensory Perception Action \& Cognition Team - ImpAct, Lyon Neuroscience Research Center, INSERM U1028, CNRS U5292, Lyon 1 University, 16 avenue du Doyen Lépine, 69500 Bron, France

${ }^{\mathrm{e}}$ Center for Mind/Brain Sciences (CIMeC), University of Trento, Palazzo Fedrigotti - corso Bettini, 31, 38068 -TN, Rovereto, Italy

\section{* Corresponding author}

Véronique Boulenger

Laboratoire Dynamique Du Langage

CNRS/Université Lyon 2 UMR 5596

14 avenue Berthelot

69007 Lyon, FRANCE

veronique.boulenger@cnrs.fr 


\begin{abstract}
Embodiment of action-related language into the motor system has been extensively documented. Yet the case of sensory words, especially referring to touch, remains overlooked. We investigated the influence of verbs denoting tactile sensations on tactile perception. In Experiment 1, participants detected tactile stimulations on their forearm, preceded by tactile or non-tactile verbs by one of three delays $(170,350,500 \mathrm{~ms})$ reflecting different word processing stages. Results revealed shorter reaction times to tactile stimulations following tactile than nontactile verbs, irrespective of delay. To ensure that priming pertained to tactile, and not motor, verb properties, Experiment 2 compared the impact of tactile verbs to both action and nontactile verbs, while stimulations were delivered on the index finger. No priming emerged following action verbs, therefore not supporting the motor-grounded interpretation. Facilitation by tactile verbs was however not observed, possibly owing to methodological changes. Experiment 3, identical to Experiment 2 except that stimulation was delivered to participants' forearm, replicated the priming effect. Importantly, tactile stimulations were detected faster after tactile than after both non-tactile and action verbs, indicating that verbs' tactile properties engaged resources shared with sensory perception. Our findings suggest that language conveying tactile information can activate somatosensory representations and subsequently promote tactile detection.
\end{abstract}

\title{
Keywords
}

Embodied Cognition; Language; Touch; Tactile verbs; Somatosensory Perception 


\section{Introduction}

Theories framing human cognition within the context of the limits and opportunities offered by the human body, have received an ever growing attention over the last couple of decades. Embodied Cognition theories indeed consider high-level cognitive processes, such as language, as relying on broadly distributed neural networks shaped by the interactions of our body with the environment (Barsalou, 2010; Gallese \& Lakoff, 2005). Accordingly, linguistic processes do not only engage core language-specific perisylvian areas, but are also grounded in the sensorimotor systems. Understanding word meaning would entail re-instantiation of the sensory and motor states experienced when first encountering words (Barsalou, 2008; Fischer \& Zwaan, 2008; Pulvermüller, 2005). An overwhelming amount of work has provided substantial evidence for sensorimotor cortical activations during semantic processing of words and sentences. Most of this evidence comes from research on words denoting bodily actions (e.g., draw, kick), which offered the opportunity to investigate the functional links between language processing and the motor system. Since the seminal work by Hauk and colleagues (Hauk, Johnsrude, \& Pulvermüller, 2004) in functional Magnetic Resonance Imaging (fMRI), several neuroimaging and behavioral studies reported that (pre)motor brain regions are called upon during processing of action words, either in isolation or embedded in a sentential context, whether literal or figurative (Boulenger, Hauk, \& Pulvermüller, 2009; Desai, Binder, Conant, Mano, \& Seidenberg, 2011; Fargier et al., 2012; Glenberg \& Kaschak, 2002; Pérez-Gay Juárez, Labrecque, \& Frak, 2019; Postle, McMahon, Ashton, Meredith, \& de Zubicaray, 2008; Pulvermüller, Hauk, Nikulin, \& Ilmoniemi, 2005; Rueschemeyer, Lindemann, van Rooij, van Dam, \& Bekkering, 2010; Tettamanti et al., 2005; Tremblay \& Small, 2011; Vukovic, Feurra, Shpektor, Myachykov, \& Shtyrov, 2017; Willems, Toni, Hagoort, \& Casasanto, 2010). Moreover, kinematic recordings of grasping movements indicated that reading action verbs can interfere with concurrent movement execution. This crosstalk turned to facilitation when action words were displayed before movement onset, underlining the existence of shared neural resources between the two processes (Boulenger et al., 2006; Boulenger, Silber, et al., 2008). Despite flourishing support for motor activity during action word processing, the issue of its functional relevance to language understanding, namely whether motor regions are integral part of the comprehension network or not, remains controversial (Hauk \& Tschentscher, 2013; Hickok, 2010; Mahon, 2015; Mahon \& Caramazza, 2005; Pulvermüller, 2005; Pulvermüller \& Fadiga, 2010). Studies using electro/magnetoencephalography (EEG/MEG) reported early (within 200ms) and/or automatic motor resonance during action word processing, suggesting 
an involvement of motor circuits in lexico-semantic retrieval (Boulenger, Shtyrov, \& Pulvermüller, 2012; Hauk, Davis, Kherif, \& Pulvermüller, 2008; Mollo, Pulvermüller, \& Hauk, 2016; Moseley, Pulvermüller, \& Shtyrov, 2013; Shtyrov, Butorina, Nikolaeva, \& Stroganova, 2014; van Elk, van Schie, Zwaan, \& Bekkering, 2010). Other studies have however challenged the irrepressible nature of language-related motor activation and showed that this varies with context and occurs only when task-relevant (Aravena et al., 2014, 2012; Gianelli, Farnè, Salemme, Jeannerod, \& Roy, 2011; van Dam, Rueschemeyer, \& Bekkering, 2010). A Transcranial Magnetic Stimulation (TMS) study by Papeo and colleagues (Papeo, Vallesi, Isaja, \& Rumiati, 2009) demonstrated that motor cortex activity, as reflected by motor-evoked potentials from hand muscles, increased in a semantic task but not in a lexical syllabicsegmentation task. In addition, this motor modulation was observed when the motor cortex was stimulated at post-conceptual stages of word recognition, namely 500ms after word onset, but not at 170 and $350 \mathrm{~ms}$ post-onset. Studies in patients suffering from motor disorders have also emphasized that motor regions functionally contribute, but are not mandatory, to action word recognition (Bak, O’Donovan, Xuereb, Boniface, \& Hodges, 2001; Boulenger, Mechtouff, et al., 2008; Desai, Herter, Riccardi, Rorden, \& Fridriksson, 2015; Fernandino et al., 2013; Papeo et al., 2015). Hence, sensorimotor regions would likely supplement language understanding by providing enriched multimodal information, without being strictly necessary.

As previously outlined, embodied theories primarily found support from studies investigating the processing of words referring to actions. Other studies have endeavored to examine interactions between perceptual word processing and neural circuits for perception (Pecher, Zeelenberg, \& Barsalou, 2004; Pulvermüller \& Hauk, 2006; Richardson, Spivey, Barsalou, \& McRae, 2003; Simmons et al., 2007; Vermeulen, Corneille, \& Niedenthal, 2008; Vermeulen, Mermillod, Godefroid, \& Corneille, 2009). Kaschak and colleagues (Kaschak et al., 2005) asked participants to make sensibility or grammaticality judgements on sentences describing visual motion (upward, downward, towards or away; e.g., 'The cat climbed the tree' or 'The car approached you') while simultaneously viewing visual stimuli depicting either congruent or incongruent motion. In both tasks, reaction times were longer in the congruent condition, that is, when visual motion was in the same direction as the linguistically-described motion. The authors proposed that the involvement of neural mechanisms to process motion in a particular direction prevented them to be fully available for motion simulation in the language comprehension task, thus leading to an interference effect (see also Kaschak, Zwaan, Aveyard, $\&$ Yaxley, 2006). Such an influence of visual motion on language comprehension has also been corroborated by others (Meteyard, Zokaei, Bahrami, \& Vigliocco, 2008; Zwaan \& Taylor, 
2006). Yet, evidence for the embodiment of language in the perceptual system is scarcer if one looks at sensory modalities other than vision. In two fMRI and EEG experiments, Kiefer and colleagues (Kiefer, Sim, Herrnberger, Grothe \& Hoenig, 2008) demonstrated overlapping early (150-200ms) activation of associative auditory areas (left posterior superior and middle temporal gyri) for processing words associated with acoustic features (e.g., telephone) and for actual sound perception (see also Brunyé, Ditman, Mahoney, Walters, \& Taylor, 2010). Another fMRI study reported activity in the primary olfactory cortex - encompassing the piriform cortex and the amygdala - during reading of odor-related words (e.g., cinnamon) (González et al., 2006). In the same vein, Barrós-Loscertales and colleagues (BarrósLoscertales et al., 2012) showed that taste-related words such as "salt" sparked the primary and secondary gustatory cortices.

To date, crosstalk between language processing and the tactile sensory modality has barely been investigated. Among the rare studies, Connell and collaborators (Connell, Lynott, \& Dreyer, 2012) demonstrated that tactile (from vibrating cushions) or proprioceptive stimulation (from holding a ball) on the hands facilitated size judgement on object names, as compared to stimulation on the feet. Importantly, this effect was only found for small, manipulable objects for which such perceptual information is functionally relevant. This led the authors to conclude that body-specific tactile and proprioceptive information contributes to conceptual representations of objects. Evidence that perceptual experiences are reactivated during language comprehension also comes from the work by Brunyé and colleagues (Brunyé et al., 2012). They showed that reading sentences conveying texture-specific tactile properties influences tactile perception. Participants rated fabrics as smoother after reading smooth-related sentences (e.g., "Karen tied a long silk ribbon onto her gifts") whereas they provided rougher ratings following rough-related sentences (e.g., "Karen touched the grainy sandpaper”). Brunyé et al. (2012) designed a task that required participants to categorize the texture of fabrics, thus relying on conceptual processing which may have overlapped with sentence semantic processing.

In the present study, we sought to further assess the hypothesis of the crosstalk between language and somatosensation. To this aim, we devised a paradigm to test whether tactilerelated verbs can affect tactile detection. We specifically asked whether processing verbs referring to tactile properties (e.g., to touch) can impact the perceptual processing of tactile stimuli in a simple stimulus-detection task. We report on three behavioral experiments wherein verbs conveying tactile sensation, or not (i.e. controls), were visually displayed to participants and could be followed by a tactile stimulation on their right forearm (Experiments 1 and 3) or index finger (Experiment 2). Tactile stimulation was delivered at one of three delays following 
verb onset $(170,350$ and $500 \mathrm{~ms})$ thought to reflect the multistage nature of word processing (Barber \& Kutas, 2007; Bentin, Mouchetant-Rostaing, Giard, Echallier, \& Pernier, 1999; Hauk, Davis, Ford, Pulvermüller, \& Marslen-Wilson, 2006; Papeo et al., 2009). We predicted that, if tactile-related language processing involves somatosensory processing, tactile verbs, as compared to non-tactile verbs, would affect detection of tactile stimuli in terms of response times and/or accuracy. In line with findings that motor activation to action-related verbs occurs early (Boulenger et al., 2012; Hauk et al., 2008; van Dam et al., 2010), such an effect might already be observed at $170 \mathrm{~ms}$, namely during word lexico-semantic retrieval. Alternatively, if somatosensory brain regions are called upon during later, post-conceptual stages of word recognition (i.e. mental imagery) (Papeo et al., 2009; Tomasino, Fink, Sparing, Dafotakis, \& Weiss, 2008), influence of tactile verbs on touch detection would only occur at the longest $500 \mathrm{~ms}$ delay.

\section{Experiment 1}

\subsection{Materials and Methods}

\subsubsection{Participants}

Twenty-one healthy French native participants (9 females, age range $=18$-36 years old, mean age $=23$, mean score \pm SD from the Edinburgh handedness inventory $=70 \pm 25$, Oldfield, 1971) took part in the experiment. All had normal or corrected-to-normal vision and reported no language, motor, tactile or any other neurological disorders. They were naïve to the purpose of the study. The protocol conformed to the declaration of Helsinki and was approved by the national ethics committee (CPP SUD-EST IV 11/005). All participants gave their written inform consent and were paid for their participation.

\subsubsection{Stimuli}

Two lists of 12 French verbs each were created: tactile verbs referred to painless tactile sensation (e.g., "toucher"/to touch) whereas non-tactile verbs did not (e.g., "remplacer"/to replace). All verbs were transitive and presented in the infinitive form. The two lists were matched for psycholinguistic variables such as written and oral word frequencies, numbers of letters and syllables, as well as numbers of homophones, homographs and orthographic neighbors (see Table S1 in Appendix) taken from the Lexique 3 database (New, Pallier, Brysbaert, \& Ferrand, 2004; New, Pallier, Ferrand, \& Matos, 2001). 
Tactile stimulations consisted in short-duration $(100 \mu \mathrm{s})$, painless electrocutaneous pulses delivered by a constant current stimulator (Digitimer DS7A) through two disposable electrodes located (1 cm away) on the volar surface of participants' right forearm. Stimulation intensity was set individually to obtain about $100 \%$ detection prior to the experimental session (intensity range $=2-9.6 \mathrm{~mA})$.

\subsubsection{Procedure}

Participants were comfortably seated in front of a computer screen, with their right arm resting on a cushion, palm upwards, and their left hand placed on a keyboard. Verbs were presented 10 times each (for a total of 240 trials) on the computer screen and were followed, in $90 \%$ of the trials, by a tactile stimulation delivered on the participant's right forearm (10\% of catch trials, whereby no tactile stimulus was delivered). Tactile and non-tactile verbs were presented in a pseudo-random order (different for each participant), with no more than two consecutive presentations of the same verb and three consecutive trials from the same condition (tactile, non-tactile or catch trials).

Each trial started with a white fixation cross presented at the center of a black screen for $500 \mathrm{~ms}$, followed by a verb (in lowercase) that lasted between 970 and $1500 \mathrm{~ms}$. When present, tactile stimulation occurred at one of three possible delays following verb onset: 170,350 or $500 \mathrm{~ms}$ (Figure 1). Verbs remained on the screen for $800 \mathrm{~ms}$ or $1000 \mathrm{~ms}$ after the tactile stimulus had been delivered (i.e. six possible verb display durations: 970, 1150, 1170, 1350, 1300, 1500ms). For 9 out of 10 repetitions, each tactile and non-tactile verb was associated three times with each of the three stimulation delays, leading to a total of $36(12 \times 3)$ tactile trials and $36(12 \times 3)$ non-tactile trials for each delay. When verbs were not associated with a tactile stimulation (1 out of 10 repetitions, 12 tactile and 12 non-tactile trials), they remained on the screen for 970 or $1500 \mathrm{~ms}$. Participants were instructed that they would see task-irrelevant words on the screen and that their task was to focus on touch perception and press the space bar of the keyboard with their left index finger as quickly as possible whenever they felt a tactile stimulus on their right forearm. The next trial automatically began after a varying delay of either 800 or $1300 \mathrm{~ms}$ (black screen). The experiment was conducted with Presentation software (http://www.neurobs.com/) and lasted about $10 \mathrm{~min}$. Reaction Times (RTs) were measured as the time interval (in ms) between the onset of the electrical pulse and the participants' key press. Accuracy was assessed as the number of correct detections of the tactile stimuli. 


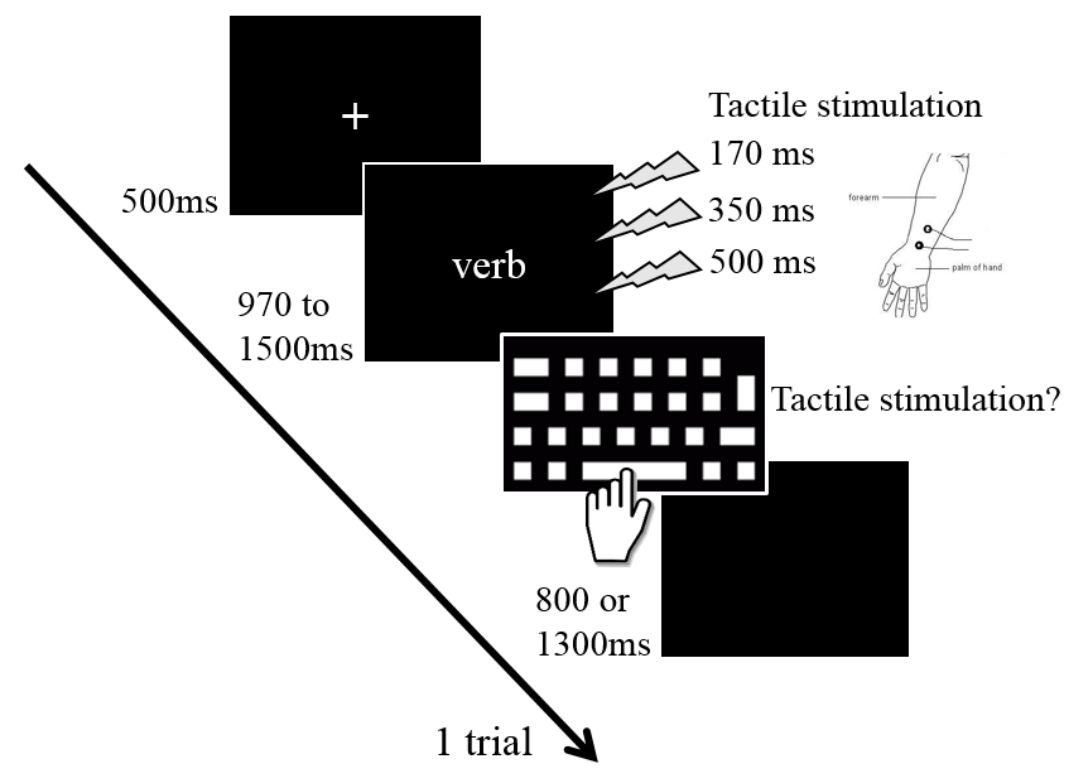

Figure 1: Experimental procedure used in the three experiments. After the display of a fixation cross for $500 \mathrm{~ms}$, a verb was presented on the screen for a duration of 970 to $1500 \mathrm{~ms}$. This verb could either be a tactile, a non-tactile or an action verb (in Experiments 2 and 3 for the latter). A tactile stimulation was then delivered on participants' right forearm (Experiments 1 and 3) or right index finger (Experiment 2). This stimulation was delivered in $90 \%$ of the trials and occurred at one of three possible delays following verb onset: 170,350 or 500ms. Participants were instructed to focus on touch perception and press the space bar of the keyboard with their left index finger as quickly as possible whenever they felt a tactile stimulus on their forearm or index finger. The next trial automatically began after a delay of 800 or $1300 \mathrm{~ms}$.

\subsubsection{Statistics}

Linear mixed model analyses were conducted with the $\mathrm{R}$ program for statistical computing $(\mathrm{R}$ Core Team, 2018) on participants' individual raw RTs (on correct responses only, for the 90\% of trials accompanied by tactile stimulation). We used lme4 (Bates, Mächler, Bolker, \& Walker, 2015), lmerTest (Kuznetsova, Brockhoff, \& Christensen, 2017) and car (Fox \& Weisberg, 2011) packages. The package "car" was used to obtain main effects from the output of "lme4". We modelled the data to analyze the effects of Stimulation Delay (170ms vs $350 \mathrm{~ms}$ vs $500 \mathrm{~ms}$ ) and Verb Category (tactile vs non-tactile) as well as their potential interaction, while taking into account the variability between subjects and items as well as the fact that each item was repeated 10 times during the experiment (i.e. Repetition effect). An analysis of variance showed that the model including Subjects, Items and Repetition as random effects ((1|Subjects) + (1|Items) + $(1 \mid$ Repetition), Akaike Information Criterion AIC = 38811) fitted the data significantly better 
than the model including Subjects only ((1|Subjects), AIC $\left.=38824, \chi^{2}(1)=17.26, p<.001\right)$. Our model for analyzing raw RTs therefore included Stimulation Delay and Verb Category as fixed factors, and Subjects, Items and Repetition as random effects. To check the robustness of our results, we performed the same mixed model analysis on log-transformed RTs as well. Finally, participants' accuracy was analyzed with a binomial generalized linear mixed model including the same fixed factors (i.e. Stimulation Delay and Verb Category) and random effects (i.e. Subjects, Items and Repetition) as in the RT analysis.

\subsection{Results}

The analysis revealed a significant main effect of Stimulation Delay $\left(\chi^{2}(2)=265.83, p<.001\right)$ on raw RTs. Participants took more time to respond to the tactile stimuli when they were delivered $170 \mathrm{~ms}$ after verb onset (mean RT $=416 \mathrm{~ms} \pm 138)$ rather than after $350 \mathrm{~ms}(362 \mathrm{~ms}$ $\pm 131 ; S E=4.53, t=12.45, p<.001)$ and 500ms $(347 \mathrm{~ms} \pm 129 ; S E=4.55, t=15.56, p<.001$; Figure 2A). RTs were also significantly longer in the $350 \mathrm{~ms}$ condition as compared to the $500 \mathrm{~ms}$ condition $(S E=4.38, t=3.28, p=.001)$. Most interestingly, a significant main effect of Verb Category was observed $\left(\chi^{2}(1)=3.82, p=.050\right)$. Participants detected tactile stimulation earlier when preceded by tactile verbs (mean RT $=369 \mathrm{~ms} \pm 134$ ) as opposed to non-tactile verbs (mean RT $=378 \mathrm{~ms} \pm 137$; Figure $3 \mathrm{~A}$ ). The two fixed factors did not significantly interact $\left(\chi^{2}(2)\right.$ $=.873, p=.646)$. The same analysis on $\log$ RTs confirmed this pattern of results, namely significant main effects of Stimulation Delay $\left(\chi^{2}(2)=325.50, p<.001\right)$ and Verb Category $\left(\chi^{2}(1)\right.$ $=5.06, p=.024)$, with no interaction between the two $\left(\chi^{2}(2)=2.20, p=.332\right)$.

Participants' accuracy was also significantly affected by the Delay between verb onset and tactile stimulation $\left(\chi^{2}(2)=50.87, p<.001\right)$, with lower performance at the shortest $170 \mathrm{~ms}$ delay (mean score $=67.91 \% \pm 46.7)$ than at 350ms $(78.12 \% \pm 41.3 ; S E=.094, z=6.74, p<.001)$ and $500 \mathrm{~ms}(75.90 \% \pm 42.8 ; S E=.092, z=5.24, p<.001)$. There was no significant difference between the 350 and $500 \mathrm{~ms}$ conditions $(S E=.096, z=-1.55, p=.120)$. Verb Category did not interact with Stimulation Delay $\left(\chi^{2}(1)=2.99, p=.223\right)$ nor affected participants' accuracy $\left(\chi^{2}(1)\right.$ $=.003, p=.953)$. Mean scores were comparable for tactile stimulations preceded by tactile verbs $(74.0 \% \pm 43.8)$ and non-tactile verbs $(73.9 \% \pm 43.9)$. 
A)

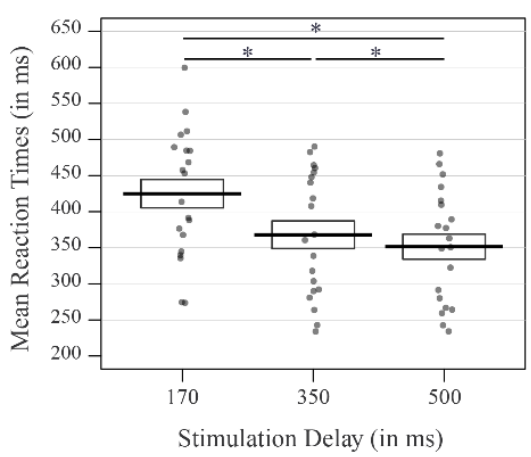

B)

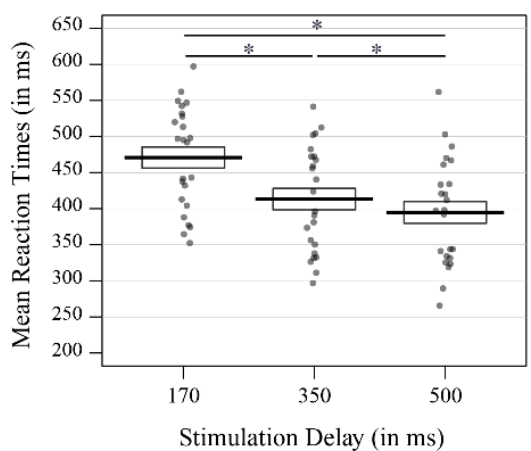

C)

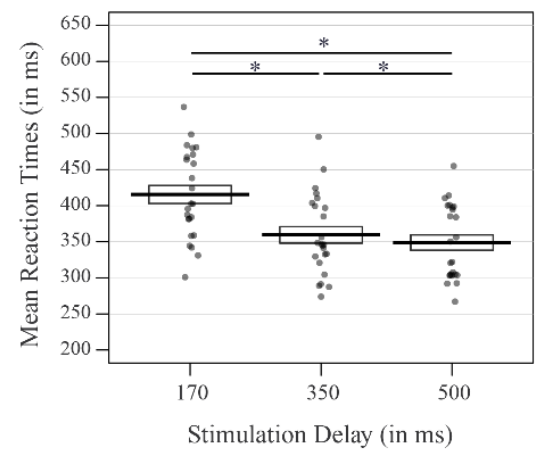

Figure 2: Effect of Stimulation Delay on the detection of tactile stimulations in A) Experiment 1, B) Experiment 2 and C) Experiment 3. Participants' mean Reaction Times (RTs) to detect tactile stimuli as a function of the delay between verb onset and tactile stimulation (170, 350 or 500ms). The bold lines represent RTs averaged over all participants in each condition, standard errors are illustrated by rectangles. Each dot represents the mean RT for one participant in the corresponding condition. * indicate significant differences between conditions.

\subsection{Summary of Experiment 1}

Results of Experiment 1 reveal that, as compared to non-tactile verbs, verbs denoting tactile sensations significantly boost tactile detection on the forearm. While this can be taken as preliminary evidence in favor of a crosstalk between language and somatosensation, it should be noted that the French tactile verbs used in this experiment do not only refer to perceptual sensation, but also to manual actions. For instance, "toucher" (to touch) depicts both the action of touching something/somebody and the tactile sensation evoked by touching. Accordingly, the reported facilitation effect could pertain, at least in part, to the motor component of verbs instead of their tactile properties per se. To tease apart the motor and tactile components of this phenomenon, we conducted a second experiment wherein tactile verbs were compared both to verbs denoting manual actions without any particular sensation (e.g., "arroser"/to water) and to non-tactile verbs. In addition, we reasoned that if motor characteristics of tactile verbs primed motor response to tactile stimuli in Experiment 1, the result should be even stronger when stimulation is applied to the same effector as the one used to perform the depicted actions. Along this view, facilitation (i.e. shorter RTs) should be observed both for tactile and action verbs, with even stronger effects for the latter. To test this prediction, we delivered tactile stimulations on participants' right index finger (vs right forearm in Experiment 1). 
Alternatively, if tactile properties of verbs do underlie the facilitation effect observed in Experiment 1, detection of tactile stimuli should be faster only in the tactile verb condition.

\section{Experiment 2}

\subsection{Materials and Methods}

\subsubsection{Participants}

Twenty-four healthy French native students from the University of Lyon (13 females, age range $=19-28$ years old, mean age $=22$ years old; mean handedness score $=76 \pm 20$ ) volunteered for the experiment. None of them had participated in Experiment 1. They reported normal or corrected-to-normal vision and no language, motor, tactile or neurological disorders. The protocol conformed to the declaration of Helsinki and was approved by the national ethics committee (CPP SUD-EST IV 11/005). All participants gave their written inform consent and were paid for their participation.

\subsubsection{Stimuli}

The stimuli consisted in the 12 tactile verbs and 8 (out of 12) non-tactile verbs from Experiment 1. Note that four new non-tactile items without any motor nor tactile component were selected (e.g., "guider"/to guide in Experiment 1 was replaced by "inciter"/to encourage). We additionally created a list of 12 non-tactile action-related verbs referring to hand actions but without evoking any strong tactile sensation (e.g., "arroser"/to water). The three lists of verbs were matched for the same psycholinguistic variables as in Experiment 1 (see Table S2 in Appendix). The somatosensory-relatedness (tactile) and action-relatedness of the three categories of verbs were assessed in a pilot rating study conducted in nineteen naïve French native speakers (different from the participants in Experiments 1 and 2). They were instructed to read the 36 verbs and rate, on a 6-point scale, the strength with which each verb evokes a tactile sensation and an action. ANOVAs revealed a significant main effect of Verb Category on both dependent variables (somatosensory-relatedness: $\mathrm{F}(2,33)=285.8, p<.001$; actionrelatedness: $\mathrm{F}(2,33)=160.9, p<.001$; see Table S3 in Appendix). Tactile verbs were rated as significantly more related to tactile sensation (mean $=4.28 \pm 0.40)$ than action verbs $(2.04 \pm 0.59$; $t=-13.15, p<.001)$ and non-tactile (abstract) verbs $(0.22 \pm 0.14 ; t=-23.87, p<.001)$. Conversely, action verbs were judged as more related to actions $(4.27 \pm 0.20)$ than non-tactile verbs $(1.88 \pm 0.40 ; t=-16.46, p<.001)$ and tactile verbs $(3.97 \pm 0.42$, although the difference did not reach significance in this case, $t=2.05, p=.11$ ). 
Verbs were accompanied by a tactile stimulation delivered through electrocutaneous pulses using the same previously described material and procedures, except that electrodes were placed on the second and third phalanxes of the participants' right index finger (duration: $100 \mu \mathrm{s}$; intensity range: 2.5 to $7.7 \mathrm{~mA}$ ). As in Experiment 1, this stimulation was delivered in $90 \%$ of the trials and at three possible delays after verb onset (170, 350 or $500 \mathrm{~ms})$.

\subsubsection{Procedure}

The experimental procedure was identical to the one used in Experiment 1. At the end of the experiment, participants were asked to rate the somatosensory- and action-relatedness of verbs using the same procedure as described in the Methods section. The total duration of the experiment was approximately $20 \mathrm{~min}$.

\subsubsection{Statistics}

Data from verb ratings were analyzed with ANOVAs including somatosensory- and actionrelatedness scores as dependent variables and Verb Category as the fixed factor. For the main experiment, the same analyses as in Experiment 1 were carried out on participants' individual raw RTs to detect tactile stimulations, as well as on log transformed RTs, using linear mixed models. Including Repetition of items with Subjects and Items as random effects significantly improved the fit of the model (AIC value $=69476$ ) as compared to when only the Subjects effect was entered (AIC $=69487, \chi^{2}(1)=15.297, p<.001$ ). The final model used to analyze raw RTs and $\log$ RTs thus included Stimulation Delay (170, 350 and 500ms) and Verb Category (tactile, non-tactile and action verbs) as fixed factors and Subjects, Items and Repetition as random effects. Participants' accuracy was analyzed with a binomial generalized mixed model including the same factors.

\subsection{Results}

\subsubsection{Rating scores}

Analyses on participants' verb ratings confirmed the main effect of Verb Category on word somatosensory-relatedness $(\mathrm{F}(2,33)=169.7, p<.001)$. Tactile verbs were judged as significantly more associated with tactile sensation $(4.31 \pm 0.31)$ than both non-tactile $(0.77$ $\pm 0.32, t=-18.31, p<.001)$ and action verbs $(2.21 \pm 0.69, t=-10.86, p<.001)$. An effect of Verb Category on word action-relatedness was also found $(\mathrm{F}(2,33)=59.08, p<.001)$, with action verbs being significantly more related to actions $(3.65 \pm 0.27)$ than tactile verbs $(3.17$ 
$\pm 0.37 ; t=3.32, p=.006)$ and non-tactile verbs $(2.11 \pm 0.41 ; t=-10.62, p<.001$; see Table S3 in Appendix).

\subsubsection{Tactile detection}

The mixed model assessing verb influence on tactile detection revealed a significant main effect of Stimulation Delay $\left(\chi^{2}(2)=427.71, p<.001\right)$, with longer responses to tactile stimulation as the delay from verb onset decreased. Mean RTs in the $170 \mathrm{~ms}$ condition (mean $=464 \mathrm{~ms} \pm 156$ ) were significantly longer than those at $350 \mathrm{~ms}$ (mean $=405 \mathrm{~ms} \pm 137 ; S E=4.11, t=15.16, p<$ $.001)$ and 500ms (mean $=389 \mathrm{~ms} \pm 129 ; S E=4.08, t=19.98, p<.001)$. The $350 \mathrm{~ms}$ and $500 \mathrm{~ms}$ conditions also significantly differed from each other $(S E=3.96, t=4.86, p<.001$; Figure $2 \mathrm{~B})$. Contrary to Experiment 1, no main effect of Verb Category was observed $\left(\chi^{2}(2)=1.81, p=\right.$ .405), indicating that RTs to tactile stimuli did not differ when these stimuli were preceded by tactile verbs $($ mean $=414 \mathrm{~ms} \pm 139)$, non-tactile verbs $($ mean $=419 \mathrm{~ms} \pm 147)$, or action verbs (mean $=418 \mathrm{~ms} \pm 145$; Figure $3 \mathrm{~B})$. No interaction between the two fixed factors was found $\left(\chi^{2}(4)\right.$ $=2.44, p=.654)$. The same results were obtained on log-transformed RTs with only a significant main effect of Stimulation Delay $\left(\chi^{2}(2)=381.48, p<.001\right)$, whereas Verb Category did not affect performance $\left(\chi^{2}(2)=.588, p=.745\right)$, nor interacted with Stimulation Delay $\left(\chi^{2}(4)\right.$ $=.497, p=.973)$.

The analysis on participant's accuracy to detect tactile stimuli revealed a significant main effect of Stimulation Delay $\left(\chi^{2}(2)=93.67, p<.001\right)$, with lower scores at $170 \mathrm{~ms}$ (mean score $=$ $65.81 \% \pm 47.44)$ than at $350 \mathrm{~ms}(72.83 \% \pm 44.48 ; S E=.065, z=5.93, p<.001)$ and $500 \mathrm{~ms}$ $(76.08 \% \pm 42.67 ; S E=.067, z=8.75, p<.001)$. The 350 and $500 \mathrm{~ms}$ conditions also significantly differed from each other $(S E=.068, z=2.87, p=.004)$. Neither the interaction between Stimulation Delay and Verb Category nor the main effect of Verb Category were significant $\left(\chi^{2}(2)=3.25, p=.197\right.$ and $\chi^{2}(4)=1.57, p=.814$ respectively). Participants' accuracy to tactile stimuli was comparable for tactile verbs $(72.37 \% \pm 44.72)$, non-tactile verbs $(71.87 \% \pm 44.96)$ and action verbs $(70.48 \% \pm 45.61)$.

\subsection{Summary of Experiment 2}

Experiment 2 aimed at testing whether the priming effect from tactile verbs observed in Experiment 1 could pertain to words' motor properties instead of their tactile ones. The results do not show any effect of verb category on tactile detection: as compared to non-tactile abstract 
verbs, neither tactile nor action verbs affected responses to tactile stimulations on the index finger. Such a pattern does not conform to the predictions of a previous motor-grounded effect. Indeed, despite the stimulation of the index finger may have enhanced the motor bias in Experiment 2, motor response to tactile stimulations was not facilitated when action verbs (conveying tactile sensation or not) were displayed. Altogether, it would therefore be tempting to conclude that tactile detection was faster following tactile verbs in Experiment 1 because words' tactile properties per se triggered somatosensory representations that are shared with sensory perception. However, this facilitation effect was not replicated in Experiment 2. This was unexpected as verb ratings performed by two independent groups of participants (including those in Experiment 2) highlighted that tactile verbs were indeed more highly associated with tactile sensation than the two other verb categories. The semantic distinction between tactile and non-tactile verbs was furthermore sharpened in Experiment 2 as the non-tactile condition only included abstract verbs that did not evoke any action nor tactile sensation. Such lack of priming by tactile verbs in Experiment 2 may pertain to methodological considerations, and particularly to the change of stimulation site from the right forearm to the right index finger. As discussed before, this aimed at verifying whether the priming effect resulted from (hand) action rather than tactile properties of verbs. Tactile sensitivity, as measured with two-point discrimination tasks for instance, tends to be lower on the fingers than on the volar surface of the forearm (Mancini et al., 2014; Morioka, Whitehouse, \& Griffin, 2008; Tong, Mao, \& Goldreich, 2013; Weinstein, 1968). Yet, mean reaction times to detect tactile stimulations were generally longer in Experiment 2 (stimulation delivered on the index finger; overall mean RT $=418.35 \mathrm{~ms} \pm 68.1$ ) than in Experiment 1 (stimulation on the forearm; overall mean $\mathrm{RT}=$ $370.75 \mathrm{~ms} \pm 82.8, t(38)=-2.076, p=.045)$. It is therefore possible that overall longer RTs may have lowered task sensitivity, in turn preventing the priming effect by tactile verbs to emerge. To verify this interpretation, we conducted a third experiment which was entirely similar to Experiment 2 except that tactile stimulations were delivered on participants' right forearm, as in Experiment 1. If the priming effect by tactile verbs vanished in Experiment 2 because stimulating the index finger lowered task sensitivity, applying the stimulation again to the forearm should restore the effect: tactile stimulations should be detected faster when preceded by tactile verbs, as compared to non-tactile and action verbs. 
A)

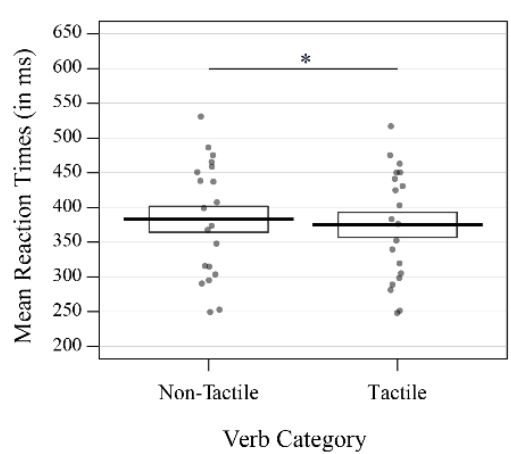

B)

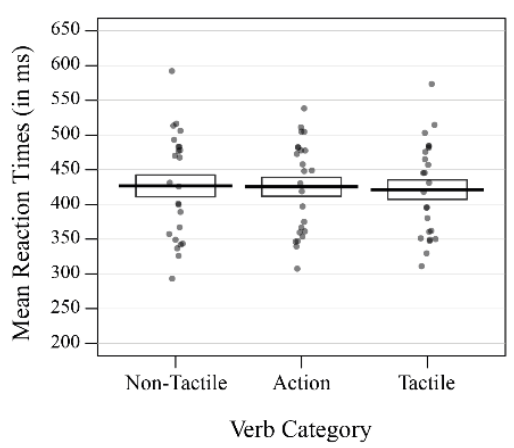

C)

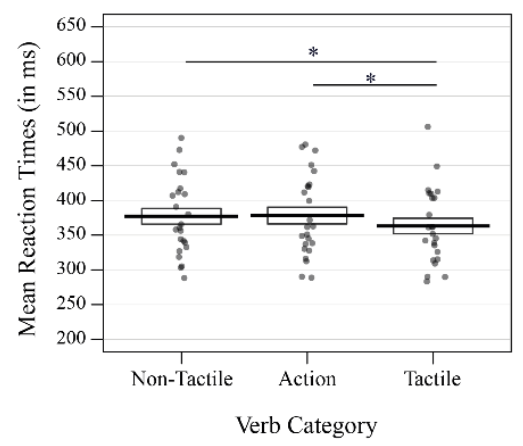

Figure 3: Effect of Verb Category on the detection of tactile stimulations in A) Experiment 1, B)

Experiment 2 and C) Experiment 3. Mean RTs of participants to detect tactile stimulations when they were preceded by non-tactile, tactile and action verbs depending on the experiment. The group mean, individual RTs and standard errors in each condition are represented by bold lines, dots and rectangles respectively. * stand for significant differences between conditions.

\section{Experiment 3}

\subsection{Materials and Methods}

\subsubsection{Participants}

A new group of twenty-four healthy right-handed French native participants (age range $=18$ 30 years old $)^{1}$, also recruited from the student population of the University of Lyon, volunteered for the experiment. They reported normal or corrected-to-normal vision and no language, motor, tactile or neurological disorders. The protocol conformed to the declaration of Helsinki and was approved by the national ethics committee (CPP SUD-EST IV 11/005). All participants gave their written inform consent and were paid for their participation.

\subsubsection{Stimuli, procedure and statistics}

The stimuli and experimental procedure were identical to those in Experiment 2 except that the tactile stimulation was delivered on the participant's right forearm as in Experiment 1. For verb ratings, ANOVAs were conducted on somatosensory- and action-relatedness variables including Verb Category as the fixed factor. Mixed model analyses were used to assess the

\footnotetext{
${ }^{1}$ Due to the closure of the laboratory because of Covid-19 containment measures, we are unable to provide some of the information regarding participants. Please note that these participants were recruited according to the same criteria as in the two previous experiments (aged between 18 and 30 years old; right-handed as assessed with the Edinburgh handedness inventory, Oldfield, 1971).
} 
influence of Stimulation Delay and Verb Category on participants' RTs to detect tactile stimulations. Analyses of variance showed that the data were best modelled when including Subjects, Items and Repetition as random effects $(\mathrm{AIC}=80327)$ than when considering Subjects only $\left(\mathrm{AIC}=80357, \chi^{2}(1)=33.66, p<.001\right)$. The model used to analyze raw RTs and $\log$ RTs therefore included Stimulation Delay (170, 350 and 500ms) and Verb Category (tactile, non-tactile and action verbs) as fixed factors and Subjects, Items and Repetition as random effects. The same factors and effects were entered in the binomial generalized mixed model used to analyze participants' accuracy to detect tactile stimulation.

\subsection{Results}

\subsubsection{Rating scores}

ANOVAs on verb ratings showed that Verb Category significantly affected the way participants evaluated word somatosensory-relatedness $(\mathrm{F}(2,33)=231.9, p<.001)$. They judged tactile verbs as significantly more related to tactile sensation $(4.48 \pm 0.19)$ than non-tactile $(0.62 \pm 0.27$, $t=-21.28, p<.001)$ and action verbs $(2.03 \pm 0.69, t=-13.48, p<.001)$. An effect of Verb Category on word action-relatedness was also observed $(\mathrm{F}(2,33)=114.6, p<.001)$ : action verbs were significantly more associated with actions $(3.78 \pm 0.35)$ than tactile verbs $(3.38 \pm 0.42 ; t=$ 2.63, $p=.033)$ and non-tactile verbs $(1.62 \pm 0.33 ; t=-14.23, p<.001$; see Table S3 in Appendix).

\subsubsection{Tactile detection}

Mixed model analyses revealed a significant main effect of Stimulation Delay $\left(\chi^{2}(2)=540.41\right.$, $p<.001$ ), with longer responses to tactile stimulation for shorter delays between verb onset and stimulation. Participants took more time to detect the stimulation at $170 \mathrm{~ms}$ (mean $=409 \mathrm{~ms}$ $\pm 121)$ than at $350 \mathrm{~ms}($ mean $=356 \mathrm{~ms} \pm 111 ; S E=3.03, t=17.96, p<.001)$ and $500 \mathrm{~ms}(\mathrm{mean}=$ $346 \mathrm{~ms} \pm 108 ; S E=3.02, t=21.99, p<.001$; Figure $2 \mathrm{C}$ ). The $350 \mathrm{~ms}$ and $500 \mathrm{~ms}$ conditions also significantly differed from each other $(S E=2.95, t=4.10, p<.001)$. Most importantly, a significant effect of Verb Category was found $\left(\chi^{2}(2)=39.63, p<.001\right.$; Figure $\left.3 C\right)$ : participants exhibited shorter RTs to tactile stimulations when preceded by tactile verbs (mean $=358 \mathrm{~ms} \pm$ 108 ) than by both non-tactile (mean $=374 \mathrm{~ms} \pm 120 ; S E=2.99, t=5.26, p<.001)$ and action verbs $($ mean $=376 \mathrm{~ms} \pm 120 ; S E=2.99, t=5.56, p<.001)$. Moreover, RTs in the non-tactile and action verbs conditions did not significantly differ from each other $(S E=2.99, t=-0.31, p$ $=.754)$. The Stimulation Delay $\times$ Verb Category interaction was not significant $\left(\chi^{2}(4)=6.89\right.$, 
$p=.141)$. The analysis on log-transformed RTs confirmed the overall pattern with significant main effects of Stimulation Delay $\left(\chi^{2}(2)=671.53, p<.001\right)$ and Verb Category $\left(\chi^{2}(2)=38.97\right.$, $p<.001)$ and lack of interaction between the two factors although barely significant $\left(\chi^{2}(4)=\right.$ $9.24, p=.055)$.

The mixed model applied to participants' accuracy only revealed a significant effect of Stimulation Delay $\left(\chi^{2}(2)=128.71, p<.001\right)$ : participants detected tactile stimulations more accurately when they followed action verb onset from 350ms (mean $=88.32 \% \pm 32.11 ; S E=$ $0.08, z=8.83, p<.001)$ and $500 \mathrm{~ms}($ mean $=89.14 \% \pm 31.11 ; S E=.08, z=9.74, p<.001)$ than from $170 \mathrm{~ms}$ (mean $=79.88 \% \pm 40.10)$. There was no significant difference between the $350 \mathrm{~ms}$ and 500ms conditions $(S E=.09, z=.976, p=.329)$. Verb Category did not significantly interact with Stimulation Delay $\left(\chi^{2}(4)=.428, p=.980\right)$ nor affected participants' accuracy $\left(\chi^{2}(2)=1.23\right.$, $p=.540)$. The tactile stimulations were detected with the same accuracy when tactile verbs $($ mean $=85.59 \% \pm 35.11)$, non-tactile verbs $($ mean $=86.32 \% \pm 34.36)$ and action verbs $($ mean $=$ $85.42 \% \pm 35.29)$ were displayed.

\section{Discussion}

The present study sought to test the hypothesis that language could be cognitively embodied into the tactile modality. Embodied cognition theories, indeed, would predict that somatosensation may also contribute to ground language comprehension, but this prediction has scarcely been examined so far. To fill this gap, we assessed whether processing of verbs describing tactile sensation, as opposed to non-tactile verbs (Experiments 1 to 3 ) and action verbs (Experiments 2 and 3), specifically affects the detection of tactile stimuli. By varying the delay between verb onset and tactile stimulation, we furthermore examined whether such crosstalk may occur at the lexico-semantic stage of word retrieval or later, during postconceptual processing.

Results from the three experiments first show that performance to detect tactile stimulations decreased, as reflected by longer reaction times and lower accuracy, when tactile stimuli followed verb onset with a short delay of $170 \mathrm{~ms}$ relative to 350 and $500 \mathrm{~ms}$. Reaction times were also longer at $350 \mathrm{~ms}$ than at $500 \mathrm{~ms}$, and this was observed independently of verb category. Lexico-semantic access during written word processing is thought to occur within $150-200 \mathrm{~ms}$ after word onset (Barber \& Kutas, 2007; Bentin et al., 1999; Hauk et al., 2006). The longer reaction times and lower accuracy for the $170 \mathrm{~ms}$ delay could thus indicate substantial cognitive 
cost when lexical access occurred simultaneously with the processing of tactile stimulations. Alternatively, this pattern may also reflect general expectancy effects (Hobeika, Taffou, Carpentier, Warusfel, \& Viaud-Delmon, 2019; Kandula, Van der Stoep, Hofman, \& Dijkerman, 2017; Näätänen, 1970; Umbach, Schwager, Frensch, \& Gaschler, 2012). The longer the delay, the more confident participants were that the tactile stimulation was about to be delivered, hence shortening reactions times and increasing accuracy for tactile detection.

Most interestingly for the purposes of the present study, Experiments 1 and 3 revealed a priming effect of tactile verbs on tactile detection: participants from two different groups were respectively $9 \mathrm{~ms}$ and $16 \mathrm{~ms}$ faster in responding to tactile stimulations delivered on their forearm when tactile $v s$ non-tactile verbs were displayed. These findings provide new support for the embodiment of language into the perceptual system (Barsalou, 1999, 2008) and more specifically into tactile perception. As outlined in the Introduction, only few studies have investigated the interactions between linguistic processes and somatosensation, and when they did, the designed tasks usually relied on conceptual processing (evaluation of textures in Brunyé et al., 2012; object size judgement in Connell et al., 2012). Here we show that processing of verbs referring to tactile sensations boosts relatively low-level aspects of tactile perception, thus suggesting that word representations and perceptual processing may share common neural resources (see van Dantzig, Pecher, Zeelenberg, \& Barsalou, 2008 for an effect from perceptual processing to conceptual processing using visual, auditory and tactile stimuli). Our results are in line with the study by Meteyard and collaborators (Meteyard, Bahrami, \& Vigliocco, 2007) in the visual domain showing modulation of low-level visual processes by motion words. In their work, listening to upward or downward motion verbs (e.g., 'rise' vs 'fall') decreased participant's sensitivity to visual motion patterns when these did not match the direction of motion expressed by words. The authors suggested that motion word processing activated lowlevel sensory brain regions and thus interfered with detection of incongruent motion stimuli. Along the same line, Ostarek and Huettig (2017) reported that spoken object words triggered low-level visual representations and consequently facilitated the detection of object pictures that were otherwise invisible in a continuous flash suppression paradigm. By varying the delay between word and picture onset, they furthermore showed that this effect occurred within 200400ms post-word onset, thus suggesting that low-level visual attributes are accessed rapidly from language input. In agreement with these studies, Goldberg and colleagues (Goldberg, Perfetti, \& Schneider, 2006) demonstrated that retrieving gustatory, auditory, visual and tactile knowledge from words in a property verification task activated brain regions that encode these sensory experiences (see also Simmons, Pecher, Hamann, Zeelenberg, \& Barsalou, 2003). In 
particular, deciding whether a word was associated with the property "soft" recruited the left somatosensory and (pre)motor cortices. Accordingly, the priming effect reported in our Experiments 1 and 3 may have emerged because viewing tactile-related verbs pre-activated somatosensory - and possibly motor - regions to the point it facilitated subsequent detection of tactile stimuli. As indicated by the lack of interaction with stimulation delay, this tactile advantage does not seem to depend on a specific word processing stage. This suggests that brain sensorimotor areas may be called upon early during word lexico-semantic access (Boulenger et al., 2006, 2012; Hauk \& Pulvermüller, 2004; Mollo et al., 2016; Ostarek \& Huettig, 2017; Shtyrov et al., 2014) and that this activation may persist at least until 500ms post-word onset (see, for similarly late effects, Papeo et al., 2009). The priming effect observed despite no explicit task was performed on verbs provides additional evidence that somatosensory activation occurs independently of intentional access to words' sensory properties (Connell \& Lynott, 2010; Shtyrov et al., 2014 for action words; Vermeulen et al., 2009).

The results of Experiment 2 however highlight that the benefit for tactile detection may depend on the site of tactile stimulation. Experiment 2 was aimed at providing fine-grained experimental control for one potential confound of Experiment 1, namely that tactile verbs also evoke manual actions. To test this possibility, we added non-tactile action verbs to the two other verb categories and most importantly, we delivered tactile stimulations on the effector used to perform the linguistically-depicted actions, namely on the index finger of the right hand. Changing tactile stimulation site, we did not replicate the effect of tactile verbs on tactile detection. The fact that sensory priming by tactile verbs is not immune to methodological changes could stem from processing specificities of touch-related words as compared to other modality-specific words or to action words for which crosstalk with the motor system has been reported in various paradigms. Alternatively, tactile processing per se could act differently from other modalities. Support from such an interpretation comes from studies showing tactile disadvantage in perceptual processing, namely generally slower detection of tactile stimuli than of visual and auditory targets (Spence, Nicholls, \& Driver, 2001). Modality-shifting effects (Spence \& Driver, 1997; Sutton, Hakerem, Zubin, \& Portnoy, 1961) are furthermore more costly when touch is involved: participants' responses are longer and less accurate when they have to shift away from the tactile modality (to respond to an auditory or visual stimulus) or toward this modality (while they attended another modality in the preceding trial) (Spence et al., 2001; Turatto, Galfano, Bridgeman, \& Umiltà, 2004). This asymmetry between tactile and visual/auditory processing has been described at the conceptual level as well. In a modality detection task, Connell and collaborators (Connell \& Lynott, 2010; Connell, Lynott, \& Dreyer, 
2011) reported lower accuracy and slower responses to decide whether adjectives could be experienced through touch rather than through either vision, smell, taste or audition. This was also observed for bimodal words with both visual and tactile properties (e.g., fluffy): with the same lexical items, participants were worse at processing information related to the sense of touch than to the sense of sight. The authors proposed that tactile stimuli may suffer from weak attentional endogenous control so that they would be more prone to disruption from other modalities and thus more difficult to detect successfully. Overall, the available findings therefore highlight modality-specific differences in both perceptual and conceptual processing with a disadvantage for the tactile modality.

Although future studies are needed to directly compare touch to other modalities, the results of Experiment 3 emphasize the sensitivity but also the robustness of the priming effect by tactile verbs. In this experiment, delivering the tactile stimulation again to the participants' forearm was sufficient to restore the facilitation seen in Experiment 1. In both Experiments 2 and 3, we added action verbs to abstract and tactile verbs, to examine whether verbs' motor component, instead of their tactile properties, may have facilitated tactile detection. In line with this potential interpretation, Goldberg and coworkers (Goldberg et al., 2006) reported activation not only in somatosensory but also in premotor and motor cortical regions for adjectives that evoke tactile properties. Hence, priming in Experiment 1 could result from the recruitment of motor regions which may have sped up manual responses to tactile stimulations. Findings from Experiment 3 fully replicated and extended the facilitation exerted by tactile verbs processing. Priming effects between tactile and non-tactile verbs were even stronger in Experiment 3 $(16 \mathrm{~ms})$ than in Experiment $1(9 \mathrm{~ms}$, despite overall comparable RTs, $t(42)=.292, p=.772)$, probably owing to the refinement of the non-tactile verb category to only include abstract verbs as controls. Crucially, this third experiment revealed that tactile verbs significantly enhanced tactile detection not only when they were compared to non-tactile, but also to action verbs, with a $18 \mathrm{~ms}$ advantage. Furthermore, rating scores witnessed that actions verbs were not primarily associated with any tactile sensation. This provides solid arguments that somatosensory semantic properties of tactile verbs, and not their motor component, underlie the faster detection of tactile stimulations. In this view, tactile properties of words may have engaged the same resources as those used for sensory perception, thus boosting tactile detection, an effect which cannot be attributed to overall faster motor responses to verbs that evoke manual actions. The fact that participants did not detect tactile stimulations faster when action verbs were displayed as compared to non-tactile verbs also speaks against a motor-grounded facilitation. 


\section{Conclusion}

The present study brings new evidence in favor of the embodiment of language into perception by showing that reading tactile-related verbs speeds up the detection of tactile stimulations as compared to non-tactile and action verbs. As suggested by our third experiment, this facilitation effect most probably arises from the tactile information carried by verbs rather than from their motor properties. Beyond extending previous research, these findings demonstrate influence of word lexico-semantic processing on low-level perceptual detection which has, to the best of our knowledge, not been reported so far in the somatosensory modality. Tactile words can activate somatosensory representations that are sufficiently low-level to enhance the mere detection of tactile stimulations. Although these results provide evidence that the two processes may share common neural substrates, our results also emphasize the fickleness of the newly reported crosstalk, which could partly relate to a general tactile disadvantage in processing modalityspecific information. Future studies using different methodologies should further dig into this issue given the importance of touch in our bodily interactions with the world and consequently in the construction of grounded linguistic representations.

\section{Acknowledgements}

We would like to thank participants for taking part in the study as well as two anonymous reviewers for their helpful comments on a previous version of the manuscript. We also thank the Neuro-immersion platform of Lyon which provided the material for tactile stimulations.

\section{Funding}

The study was supported by the LabEx ASLAN (ANR-10-LABX-0081) of Université de Lyon within the program "Investissements d'Avenir" (ANR-11-IDEX-0007) of the French government operated by the ANR, and by the IHU CeSaMe ANR-10-IBHU-0003. A.F. was supported by the James S. McDonnell Scholar Award and by the ANR BLIND_TOUCH 2019 CE37.

\section{Declaration of interests}

The authors declare that they have no known competing financial interests or personal relationships that could have appeared to influence the work reported in this paper. 


\section{References}

Aravena, P., Courson, M., Frak, V., Cheylus, A., Paulignan, Y., Deprez, V., \& Nazir, T. A. (2014). Action relevance in linguistic context drives word-induced motor activity. Frontiers in Human Neuroscience, 8 . https://doi.org/10.3389/fnhum.2014.00163

Aravena, P., Delevoye-Turrell, Y., Deprez, V., Cheylus, A., Paulignan, Y., Frak, V., \& Nazir, T. (2012). Grip Force Reveals the Context Sensitivity of Language-Induced Motor Activity during “Action Words" Processing: Evidence from Sentential Negation. PLoS ONE, 7(12). https://doi.org/10.1371/journal.pone.0050287

Bak, T. H., O’Donovan, D. G., Xuereb, J. H., Boniface, S., \& Hodges, J. R. (2001). Selective impairment of verb processing associated with pathological changes in Brodmann areas 44 and 45 in the motor neurone disease-dementia-aphasia syndrome. Brain: A Journal of Neurology, 124(Pt 1), 103-120. https://doi.org/10.1093/brain/124.1.103

Barber, H. A., \& Kutas, M. (2007). Interplay between computational models and cognitive electrophysiology in visual word recognition. Brain Research Reviews, 53(1), 98-123. https://doi.org/10.1016/j.brainresrev.2006.07.002

Barrós-Loscertales, A., González, J., Pulvermüller, F., Ventura-Campos, N., Bustamante, J. C., Costumero, V., ... Ávila, C. (2012). Reading Salt Activates Gustatory Brain Regions: fMRI Evidence for Semantic Grounding in a Novel Sensory Modality. Cerebral Cortex, 22(11), 2554-2563. https://doi.org/10.1093/cercor/bhr324

Barsalou, L. W. (1999). Perceptual symbol systems. The Behavioral and Brain Sciences, 22(4), 577609; discussion 610-660. https://doi.org/10.1017/s0140525x99002149

Barsalou, L. W. (2008). Grounded Cognition. Annual Review of Psychology, 59(1), 617-645. https://doi.org/10.1146/annurev.psych.59.103006.093639

Barsalou, L. W. (2010). Grounded Cognition: Past, Present, and Future: Topics in Cognitive Science. Topics in Cognitive Science, 2(4), 716-724. https://doi.org/10.1111/j.1756-8765.2010.01115.x

Bates, D., Mächler, M., Bolker, B., \& Walker, S. (2015). Fitting Linear Mixed-Effects Models Using lme4. Journal of Statistical Software, 67(1), 1-48. https://doi.org/10.18637/jss.v067.i01

Bentin, S., Mouchetant-Rostaing, Y., Giard, M. H., Echallier, J. F., \& Pernier, J. (1999). ERP manifestations of processing printed words at different psycholinguistic levels: time course and scalp distribution. Journal of Cognitive Neuroscience, 11(3), 235-260. https://doi.org/10.1162/089892999563373

Boulenger, V., Hauk, O., \& Pulvermüller, F. (2009). Grasping Ideas with the Motor System: Semantic Somatotopy in Idiom Comprehension. Cerebral Cortex, 19(8), 1905-1914. https://doi.org/10.1093/cercor/bhn217 
Boulenger, V., Mechtouff, L., Thobois, S., Broussolle, E., Jeannerod, M., \& Nazir, T. A. (2008). Word processing in Parkinson's disease is impaired for action verbs but not for concrete nouns. Neuropsychologia, 46(2), 743-756. https://doi.org/10.1016/j.neuropsychologia.2007.10.007

Boulenger, V., Roy, A. C., Paulignan, Y., Deprez, V., Jeannerod, M., \& Nazir, T. A. (2006). Crosstalk between language processes and overt motor behavior in the first $200 \mathrm{msec}$ of processing. Journal of Cognitive Neuroscience, 18(10), 1607-1615. https://doi.org/10.1162/jocn.2006.18.10.1607

Boulenger, V., Shtyrov, Y., \& Pulvermüller, F. (2012). When do you grasp the idea? MEG evidence for instantaneous idiom understanding. NeuroImage, 59(4), 3502-3513. https://doi.org/10.1016/j.neuroimage.2011.11.011

Boulenger, V., Silber, B. Y., Roy, A. C., Paulignan, Y., Jeannerod, M., \& Nazir, T. A. (2008). Subliminal display of action words interferes with motor planning: A combined EEG and kinematic study. Journal of Physiology-Paris, 102(1-3), 130-136. https://doi.org/10.1016/j.jphysparis.2008.03.015

Brunyé, T. T., Ditman, T., Mahoney, C. R., Walters, E. K., \& Taylor, H. A. (2010). You heard it here first: Readers mentally simulate described sounds. Acta Psychologica, 135(2), 209-215. https://doi.org/10.1016/j.actpsy.2010.06.008

Brunyé, T. T., Walters, E. K., Ditman, T., Gagnon, S. A., Mahoney, C. R., \& Taylor, H. A. (2012). The fabric of thought: priming tactile properties during reading influences direct tactile perception. Cognitive Science, 36(8), 1449-1467. https://doi.org/10.1111/j.15516709.2012.01268.x

Connell, L., \& Lynott, D. (2010). Look but don't touch: Tactile disadvantage in processing modalityspecific words. Cognition, 115(1), 1-9. https://doi.org/10.1016/j.cognition.2009.10.005

Connell, L., Lynott, D., \& Dreyer, F. (2012). A Functional Role for Modality-Specific Perceptual Systems in Conceptual Representations. PLOS ONE, 7(3), e33321. https://doi.org/10.1371/journal.pone.0033321

Connell, L., Lynott, D., \& Dreyer, F. R. (2011). Touching with the mind's hand: Tactile and proprioceptive stimulation facilitates conceptual size judgements.

Desai, R. H., Binder, J. R., Conant, L. L., Mano, Q. R., \& Seidenberg, M. S. (2011). The neural career of sensory-motor metaphors. Journal of Cognitive Neuroscience, 23(9), 2376-2386.

Desai, R. H., Herter, T., Riccardi, N., Rorden, C., \& Fridriksson, J. (2015). Concepts Within Reach: Action Performance Predicts Action Language Processing in Stroke. Neuropsychologia, 71, 217-224. https://doi.org/10.1016/j.neuropsychologia.2015.04.006

Fargier, R., Paulignan, Y., Boulenger, V., Monaghan, P., Reboul, A., \& Nazir, T. A. (2012). Learning to associate novel words with motor actions: Language-induced motor activity following short training. Cortex, 48(7), 888-899. https://doi.org/10.1016/j.cortex.2011.07.003 
Fernandino, L., Conant, L. L., Binder, J. R., Blindauer, K., Hiner, B., Spangler, K., \& Desai, R. H. (2013). Parkinson's Disease Disrupts Both Automatic and Controlled Processing of Action Verbs. Brain and Language, 127(1), 65-74. https://doi.org/10.1016/j.bandl.2012.07.008

Fischer, M. H., \& Zwaan, R. A. (2008). Embodied language: a review of the role of the motor system in language comprehension. Quarterly Journal of Experimental Psychology (2006), 61(6), 825-850. https://doi.org/10.1080/17470210701623605

Fox, J., \& Weisberg, S. (2011). An $\{R\}$ Companion to Applied Regression, Third Edition. Retrieved from https://socialsciences.mcmaster.ca/jfox/Books/Companion/

Gallese, V., \& Lakoff, G. (2005). The Brain's concepts: the role of the Sensory-motor system in conceptual knowledge. Cognitive Neuropsychology, 22(3-4), 455-479.

https://doi.org/10.1080/02643290442000310

Gianelli, C., Farnè, A., Salemme, R., Jeannerod, M., \& Roy, A. C. (2011). The Agent is Right: When Motor Embodied Cognition is Space-Dependent. PLoS ONE, 6(9), e25036. https://doi.org/10.1371/journal.pone.0025036

Glenberg, A. M., \& Kaschak, M. P. (2002). Grounding language in action. Psychonomic Bulletin \& Review, 9(3), 558-565.

Goldberg, R. F., Perfetti, C. A., \& Schneider, W. (2006). Perceptual Knowledge Retrieval Activates Sensory Brain Regions. Journal of Neuroscience, 26(18), 4917-4921. https://doi.org/10.1523/JNEUROSCI.5389-05.2006

González, J., Barros-Loscertales, A., Pulvermüller, F., Meseguer, V., Sanjuán, A., Belloch, V., \& Ávila, C. (2006). Reading cinnamon activates olfactory brain regions. NeuroImage, 32(2), 906-912. https://doi.org/10.1016/j.neuroimage.2006.03.037

Hauk, O., \& Tschentscher, N. (2013). The Body of Evidence: What Can Neuroscience Tell Us about Embodied Semantics? Frontiers in Psychology, 4, 50. https://doi.org/10.3389/fpsyg.2013.00050

Hauk, O., Davis, M. H., Kherif, F., \& Pulvermüller, F. (2008). Imagery or meaning? Evidence for a semantic origin of category-specific brain activity in metabolic imaging. European Journal of Neuroscience, 27(7), 1856-1866. https://doi.org/10.1111/j.1460-9568.2008.06143.x

Hauk, O., Davis, M. H., Ford, M., Pulvermüller, F., \& Marslen-Wilson, W. D. (2006). The time course of visual word recognition as revealed by linear regression analysis of ERP data. NeuroImage, 30(4), 1383-1400. https://doi.org/10.1016/j.neuroimage.2005.11.048

Hauk, O., Johnsrude, I., \& Pulvermüller, F. (2004). Somatotopic representation of action words in human motor and premotor cortex. Neuron, 41(2), 301-307.

Hauk, O., \& Pulvermüller, F. (2004). Neurophysiological distinction of action words in the frontocentral cortex: Neurophysiological Distinction of Action Words. Human Brain Mapping, 21(3), 191-201. https://doi.org/10.1002/hbm.10157 
Hickok, G. (2010). The role of mirror neurons in speech perception and action word semantics.

Language and Cognitive Processes, 25(6), 749-776.

https://doi.org/10.1080/01690961003595572

Hobeika, L., Taffou, M., Carpentier, T., Warusfel, O., \& Viaud-Delmon, I. (2019). Capturing the dynamics of peripersonal space by integrating expectancy effects and sound propagation properties. Journal of Neuroscience Methods, 108534.

https://doi.org/10.1016/j.jneumeth.2019.108534

Kandula, M., Van der Stoep, N., Hofman, D., \& Dijkerman, H. C. (2017). On the contribution of overt tactile expectations to visuo-tactile interactions within the peripersonal space. Experimental Brain Research, 235(8), 2511-2522. https://doi.org/10.1007/s00221-017-4965-9

Kaschak, M. P., Madden, C. J., Therriault, D. J., Yaxley, R. H., Aveyard, M., Blanchard, A. A., \& Zwaan, R. A. (2005). Perception of motion affects language processing. Cognition, 94(3), B79-B89. https://doi.org/10.1016/j.cognition.2004.06.005

Kaschak, M. P., Zwaan, R. A., Aveyard, M., \& Yaxley, R. H. (2006). Perception of Auditory Motion Affects Language Processing. Cognitive Science, 30(4), 733-744. https://doi.org/10.1207/s15516709cog0000_54

Kiefer, M, Sim, E-J, Herrnberger, B, Grothe, J, \& Hoenig, K (2008). The Sound of Concepts: Four Markers for a Link between Auditory and Conceptual Brain Systems. Journal of Neuroscience, 28(47), 12224-12230. doi:10.1523/JNEUROSCI.3579-08.2008

Kuznetsova, A., Brockhoff, P. B., \& Christensen, R. H. B. (2017). ImerTest Package: Tests in Linear Mixed Effects Models. Journal of Statistical Software, 82(13). https://doi.org/10.18637/jss.v082.i13

Mahon, B. Z. (2015). What is embodied about cognition? Language, Cognition and Neuroscience, 30(4), 420-429. https://doi.org/10.1080/23273798.2014.987791

Mahon, B. Z., \& Caramazza, A. (2008). A critical look at the embodied cognition hypothesis and a new proposal for grounding conceptual content. Journal of Physiology Paris, 102(1-3), 59-70. https://doi.org/10.1016/j.jphysparis.2008.03.004

Mancini, F., Bauleo, A., Cole, J., Lui, F., Porro, C. A., Haggard, P., \& Iannetti, G. D. (2014). WholeBody Mapping of Spatial Acuity for Pain and Touch. Annals of Neurology, 75(6), 917-924. https://doi.org/10/1002/ana.24179

Moseley, R., Pulvermüller, F., \& Shtyrov, Y. (2013). Sensorimotor semantics on the spot: brain activity dissociates between conceptual categories within $150 \mathrm{~ms}$. Scientific Reports, 3(1), 1-7. https://doi.org/10.1038/srep01928

Meteyard, L., Bahrami, B., \& Vigliocco, G. (2007). Motion detection and motion verbs: language affects low-level visual perception. Psychological Science, 18(11), 1007-1013. https://doi.org/10.1111/j.1467-9280.2007.02016.x 
Meteyard, L., Zokaei, N., Bahrami, B., \& Vigliocco, G. (2008). Visual motion interferes with lexical decision on motion words. Current Biology, 18(17), R732-R733. https://doi.org/10.1016/j.cub.2008.07.016

Mollo, G., Pulvermüller, F., \& Hauk, O. (2016). Movement priming of EEG/MEG brain responses for action-words characterizes the link between language and action. Cortex, 74, 262-276. https://doi.org/10.1016/j.cortex.2015.10.021

Morioka, M., Whitehouse, D. J., \& Griffin, M. J. (2008). Vibrotactile thresholds at the fingertip, volar forearm, large toe, and heel. Somatosensory \& Motor Research, 25(2), 101-112. https://doi.org/10.1080/08990220802045574

Näätänen, R. (1970). The diminishing time-uncertainty with the lapse of time after the warning signal in reaction-time experiments with varying fore-periods. Acta Psychologica, 34, 399-419. https://doi.org/10.1016/0001-6918(70)90035-1

New, B., Pallier, C., Brysbaert, M., \& Ferrand, L. (2004). Lexique 2 : A new French lexical database. Behavior Research Methods, Instruments, \& Computers, 36(3), 516-524. https://doi.org/10.3758/BF03195598

New, B., Pallier, C., Ferrand, L., \& Matos, R. (2001). Une base de données lexicales du français contemporain sur internet : LEXIQUE ${ }^{\mathrm{TM}} / / \mathrm{A}$ lexical database for contemporary french : LEXIQUE $^{\mathrm{TM}}$. L'Année psychologique, 101(3), 447-462. https://doi.org/10.3406/psy.2001.1341

Oldfield, R. C. (1971). The assessment and analysis of handedness: the Edinburgh inventory. Neuropsychologia, 9(1), 97-113.

Ostarek, M., \& Huettig, F. (2017). Spoken words can make the invisible visible - Testing the involvement of low-level visual representations in spoken word processing. Journal of Experimental Psychology: Human Perception and Performance, 43(3), 499-508. https://doi.org/10.1037/xhp0000313

Papeo, L., Cecchetto, C., Mazzon, G., Granello, G., Cattaruzza, T., Verriello, L., ... Rumiati, R. I. (2015). The processing of actions and action-words in amyotrophic lateral sclerosis patients. Cortex, 64(Supplement C), 136-147. https://doi.org/10.1016/j.cortex.2014.10.007

Papeo, L., Vallesi, A., Isaja, A., \& Rumiati, R. I. (2009). Effects of TMS on Different Stages of Motor and Non-Motor Verb Processing in the Primary Motor Cortex. PLoS ONE, 4(2), e4508. https://doi.org/10.1371/journal.pone.0004508

Pecher, D., Zeelenberg, R., \& Barsalou, L. W. (2004). Sensorimotor simulations underlie conceptual representations: Modality-specific effects of prior activation. Psychonomic Bulletin \& Review, 11(1), 164-167. https://doi.org/10.3758/BF03206477 
Pérez-Gay Juárez, F., Labrecque, D., \& Frak, V. (2019). Assessing language-induced motor activity through Event Related Potentials and the Grip Force Sensor, an exploratory study. Brain and Cognition, 135, 103572. https://doi.org/10.1016/j.bandc.2019.05.010

Postle, N., McMahon, K. L., Ashton, R., Meredith, M., \& de Zubicaray, G. I. (2008). Action word meaning representations in cytoarchitectonically defined primary and premotor cortices. NeuroImage, 43(3), 634-644. https://doi.org/10.1016/j.neuroimage.2008.08.006

Pulvermüller, F. (2005). Brain mechanisms linking language and action. Nature Reviews Neuroscience, 6(7), 576-582.

Pulvermüller, F., \& Fadiga, L. (2010). Active perception: sensorimotor circuits as a cortical basis for language. Nature Reviews Neuroscience, 11(5), 351-360. https://doi.org/10.1038/nrn2811

Pulvermüller, F., \& Hauk, O. (2006). Category-specific Conceptual Processing of Color and Form in Left Fronto-temporal Cortex. Cerebral Cortex, 16(8), 1193-1201. https://doi.org/10.1093/cercor/bhj060

Pulvermüller, F., Hauk, O., Nikulin, V. V., \& Ilmoniemi, R. J. (2005). Functional links between motor and language systems: Functional links between motor and language systems. European Journal of Neuroscience, 21(3), 793-797. https://doi.org/10.1111/j.1460-9568.2005.03900.x

Richardson, D. C., Spivey, M. J., Barsalou, L. W., \& McRae, K. (2003). Spatial representations activated during real-time comprehension of verbs. Cognitive Science, 27(5), 767-780. https://doi.org/10.1207/s15516709cog2705_4

Rueschemeyer, S.-A., Lindemann, O., van Rooij, D., van Dam, W., \& Bekkering, H. (2010). Effects of Intentional Motor Actions on Embodied Language Processing. Experimental Psychology, 57(4), 260-266. https://doi.org/10.1027/1618-3169/a000031

Shtyrov, Y., Butorina, A., Nikolaeva, A., \& Stroganova, T. (2014). Automatic ultrarapid activation and inhibition of cortical motor systems in spoken word comprehension. Proceedings of the National Academy of Sciences of the United States of America, 111(18), E1918-E1923. https://doi.org/10.1073/pnas.1323158111

Simmons, W. K., Pecher, D., Hamann, S. B., Zeelenberg, R., \& Barsalou, L. W. (2003). fMRI Evidence for Modality-Specific Processing of Conceptual Knowledge on Six Modalities [Conference Proceedings]. Retrieved November 27, 2019, from http://eprints.gla.ac.uk/112685/

Simmons, W. K., Ramjee, V., Beauchamp, M. S., McRae, K., Martin, A., \& Barsalou, L. W. (2007). A common neural substrate for perceiving and knowing about color. Neuropsychologia, 45(12), 2802-2810. https://doi.org/10.1016/j.neuropsychologia.2007.05.002

Spence, C., \& Driver, J. (1997). On measuring selective attention to an expected sensory modality. Perception \& Psychophysics, 59(3), 389-403. https://doi.org/10.3758/BF03211906

Spence, C., Nicholls, M. E. R., \& Driver, J. (2001). The cost of expecting events in the wrong sensory modality. Perception \& Psychophysics, 63(2), 330-336. https://doi.org/10.3758/BF03194473 
Sutton, S., Hakerem, G., Zubin, J., \& Portnoy, M. (1961). The effect of shift of sensory modality on serial reaction-time: A comparison of schizophrenics and normals. The American Journal of Psychology, 74, 224-232. https://doi.org/10.2307/1419407

Tettamanti, M., Buccino, G., Saccuman, M. C., Gallese, V., Danna, M., Scifo, P., ... Perani, D. (2005). Listening to action-related sentences activates fronto-parietal motor circuits. Journal of Cognitive Neuroscience, 17(2), 273-281. https://doi.org/10.1162/0898929053124965

Tomasino, B., Fink, G. R., Sparing, R., Dafotakis, M., \& Weiss, P. H. (2008). Action verbs and the primary motor cortex: A comparative TMS study of silent reading, frequency judgments, and motor imagery. Neuropsychologia, 46(7), 1915-1926. https://doi.org/10.1016/j.neuropsychologia.2008.01.015

Tong, J., Mao, O., \& Goldreich, D. (2013). Two-Point Orientation Discrimination Versus the Traditional Two-Point Test for Tactile Spatial Acuity Assessment. Frontiers in Human Neuroscience, 7. https://doi.org/10.3389/fnhum.2013.00579

Tremblay, P., \& Small, S. L. (2011). On the context-dependent nature of the contribution of the ventral premotor cortex to speech perception. NeuroImage, 57(4), 1561-1571. https://doi.org/10.1016/j.neuroimage.2011.05.067

Turatto, M., Galfano, G., Bridgeman, B., \& Umiltà, C. (2004). Space-independent modality-driven attentional capture in auditory, tactile and visual systems. Experimental Brain Research, 155(3), 301-310. https://doi.org/10.1007/s00221-003-1724-x

Umbach, V. J., Schwager, S., Frensch, P. A., \& Gaschler, R. (2012). Does Explicit Expectation Really Affect Preparation? Frontiers in Psychology, 3. https://doi.org/10.3389/fpsyg.2012.00378

van Dam, W. O., Rueschemeyer, S.-A., \& Bekkering, H. (2010). How specifically are action verbs represented in the neural motor system: An fMRI study. NeuroImage, 53(4), 1318-1325. https://doi.org/10.1016/j.neuroimage.2010.06.071

van Dantzig, S. V., Pecher, D., Zeelenberg, R., \& Barsalou, L. W. (2008). Perceptual Processing Affects Conceptual Processing. Cognitive Science, 32(3), 579-590. https://doi.org/10.1080/03640210802035365

van Elk, M., van Schie, H. T., Zwaan, R. A., \& Bekkering, H. (2010). The functional role of motor activation in language processing: Motor cortical oscillations support lexical-semantic retrieval. NeuroImage, 50(2), 665-677. https://doi.org/10.1016/j.neuroimage.2009.12.123

Vermeulen, N., Corneille, O., \& Niedenthal, P. M. (2008). Sensory load incurs conceptual processing costs. Cognition, 109(2), 287-294. https://doi.org/10.1016/j.cognition.2008.09.004

Vermeulen, N., Mermillod, M., Godefroid, J., \& Corneille, O. (2009). Unintended embodiment of concepts into percepts: Sensory activation boosts attention for same-modality concepts in the attentional blink paradigm. Cognition, 112(3), 467-472.

https://doi.org/10.1016/j.cognition.2009.06.003 
Vukovic, N., Feurra, M., Shpektor, A., Myachykov, A., \& Shtyrov, Y. (2017). Primary motor cortex functionally contributes to language comprehension: An online rTMS study. Neuropsychologia, 96, 222-229. https://doi.org/10.1016/j.neuropsychologia.2017.01.025

Weinstein, S. (1968). Intensive and extensive aspects of tactile sensitivity as a function of body part, sex and laterality. In The skin senses (Kenshalo D.R., pp. 195-222). Springfield IL: Charles C. Thomas Publisher.

Willems, R. M., Toni, I., Hagoort, P., \& Casasanto, D. (2010). Neural dissociations between action verb understanding and motor imagery. Journal of Cognitive Neuroscience, 22(10), 23872400. https://doi.org/10.1162/jocn.2009.21386

Zwaan, R. A., \& Taylor, L. J. (2006). Seeing, Acting, Understanding: Motor Resonance in Language Comprehension. Journal of Experimental Psychology: General, 135(1), 1-11. https://doi.org/10.1037/0096-3445.135.1.1 


\section{Appendix}

Table S1. Lists of tactile and non-tactile French verbs used in Experiment 1 together with their corresponding psycholinguistic variables from Lexique 3 database (New, Pallier, Brysbaert, \& Ferrand, 2004; New, Pallier, Ferrand, \& Matos, 2001). Means and Standard deviations (SD) are reported for each list. Oral Lex Freq = Oral lexical frequency; Writ Lex Freq = written lexical frequency; Nb letters = number of letters; Nb Syll = number of syllables; Nb Homogr = number of homographs: $\mathrm{Nb}$ Homoph = number of homophones; $\mathrm{Nb}$ Orth Neigh = number of orthographic neighbours. There were no significant differences along these variables between the two lists as reported in the last line of the Table.

\begin{tabular}{|c|c|c|c|c|c|c|c|}
\hline & \begin{tabular}{|c|}
$\begin{array}{c}\text { Oral Lex } \\
\text { Freq }\end{array}$ \\
\end{tabular} & \begin{tabular}{|c|} 
Writ Lex \\
Freq \\
\end{tabular} & $\begin{array}{c}\text { Nb } \\
\text { Letters }\end{array}$ & $\begin{array}{c}\text { Nb } \\
\text { Syll } \\
\end{array}$ & $\begin{array}{c}\text { Nb } \\
\text { Homogr }\end{array}$ & $\begin{array}{c}\text { Nb } \\
\text { Homoph }\end{array}$ & $\begin{array}{c}\text { Nb Orth } \\
\text { Neigh } \\
\end{array}$ \\
\hline \multicolumn{8}{|c|}{ Tactile verbs } \\
\hline caresser & 5.66 & 18.24 & 8 & 3 & 1 & 5 & 3 \\
\hline chatouiller & 0.85 & 1.69 & 11 & 3 & 1 & 6 & 2 \\
\hline effleurer & 0.62 & 4.59 & 9 & 3 & 1 & 6 & 3 \\
\hline frôler & 0.68 & 4.19 & 6 & 2 & 1 & 6 & 3 \\
\hline frotter & 4.01 & 8.99 & 7 & 2 & 1 & 9 & 6 \\
\hline gratter & 5.03 & 8.85 & 7 & 2 & 1 & 6 & 2 \\
\hline grattouiller & 0.01 & 0 & 12 & 3 & 1 & 2 & 1 \\
\hline masser & 2.98 & 2.09 & 6 & 2 & 1 & 8 & 9 \\
\hline palper & 0.97 & 4.19 & 6 & 2 & 1 & 5 & 4 \\
\hline tâter & 1.94 & 5.74 & 5 & 2 & 1 & 4 & 6 \\
\hline toucher & 49.43 & 56.15 & 7 & 2 & 2 & 12 & 8 \\
\hline tripoter & 3.09 & 2.3 & 8 & 3 & 1 & 7 & 3 \\
\hline Mean & 6.27 & 9.75 & 7.67 & 2.42 & 1.08 & 6.33 & 4.17 \\
\hline SD & 13.72 & 15.39 & 2.10 & 0.51 & 0.29 & 2.53 & 2.52 \\
\hline \multicolumn{8}{|c|}{ Non-tactile verbs } \\
\hline blâmer & 4.37 & 2.03 & 6 & 2 & 1 & 6 & 2 \\
\hline découvrir & 37.11 & 50.88 & 9 & 3 & 1 & 2 & 2 \\
\hline défier & 3.92 & 4.39 & 6 & 2 & 1 & 5 & 6 \\
\hline délaisser & 0.28 & 1.01 & 9 & 3 & 1 & 1 & 2 \\
\hline diriger & 13.94 & 17.64 & 7 & 3 & 1 & 10 & 3 \\
\hline disputer & 10.54 & 4.12 & 8 & 3 & 1 & 10 & 3 \\
\hline distraire & 7.56 & 13.38 & 9 & 2 & 1 & 1 & 2 \\
\hline guider & 7.29 & 6.76 & 6 & 2 & 1 & 6 & 2 \\
\hline héberger & 2.8 & 2.7 & 8 & 3 & 1 & 6 & 2 \\
\hline ménager & 1.73 & 8.45 & 7 & 3 & 3 & 9 & 4 \\
\hline négliger & 1.62 & 4.73 & 8 & 3 & 1 & 12 & 3 \\
\hline remplacer & 22.95 & 18.38 & 9 & 3 & 1 & 6 & 2 \\
\hline Mean & 9.69 & 11.01 & 7.67 & .67 & 1.7 & 6.17 & 2.75 \\
\hline SD & 11.31 & 14.47 & 1.23 & 0.49 & 0.58 & 3.61 & 1.22 \\
\hline Statistics & $\begin{array}{c}\mathrm{F}(1,22)= \\
.413, \\
p=.527\end{array}$ & $\begin{array}{c}\mathrm{F}(1,22)= \\
.059 \\
p=.810\end{array}$ & $\begin{array}{c}\mathrm{F}(1,22)< \\
.001 \\
p=1\end{array}$ & $\begin{array}{c}\mathrm{F}(1,22)= \\
1.478 \\
p=.237\end{array}$ & $\begin{array}{c}\mathrm{F}(1,22)= \\
.200 \\
p=.659\end{array}$ & $\begin{array}{c}\mathrm{F}(1,22)= \\
.017 \\
p=.897\end{array}$ & $\begin{array}{c}\mathrm{F}(1,22)= \\
3.083, \\
p=.093\end{array}$ \\
\hline
\end{tabular}


Table S2. Lists of tactile, non-tactile and action verbs used in Experiments 2 and 3 along with their corresponding psycholinguistic variables from Lexique 3 database. Means and Standard deviations (SD) are reported for each list. The three lists did not significantly differ in terms of these variables as shown by ANOVAs (see Table S1 for abbreviations).

\begin{tabular}{|c|c|c|c|c|c|c|c|}
\hline & \begin{tabular}{c|} 
Oral Lex \\
Freq \\
\end{tabular} & \begin{tabular}{c|} 
Writ Lex \\
Freq \\
\end{tabular} & $\begin{array}{c}\text { Nb } \\
\text { Letters }\end{array}$ & $\begin{array}{c}\text { Nb } \\
\text { Syll } \\
\end{array}$ & $\begin{array}{c}\text { Nb } \\
\text { Homogr }\end{array}$ & $\begin{array}{c}\text { Nb } \\
\text { Homoph }\end{array}$ & $\begin{array}{c}\text { Nb Orth } \\
\text { Neigh }\end{array}$ \\
\hline \multicolumn{8}{|c|}{ Tactile verbs } \\
\hline caresser & 5.66 & 18.24 & 8 & 3 & 1 & 5 & 3 \\
\hline chatouiller & 0.85 & 1.69 & 11 & 3 & 1 & 6 & 2 \\
\hline effleurer & 0.62 & 4.59 & 9 & 3 & 1 & 6 & 3 \\
\hline frôler & 0.68 & 4.19 & 6 & 2 & 1 & 6 & 3 \\
\hline frotter & 4.01 & 8.99 & 7 & 2 & 1 & 9 & 6 \\
\hline gratter & 5.03 & 8.85 & 7 & 2 & 1 & 6 & 2 \\
\hline grattouiller & 0.01 & 0,00 & 12 & 3 & 1 & 2 & 1 \\
\hline masser & 2.98 & 2.09 & 6 & 2 & 1 & 8 & 9 \\
\hline palper & 0.97 & 4.19 & 6 & 2 & 1 & 5 & 4 \\
\hline tâter & 1.94 & 5.74 & 5 & 2 & 1 & 4 & 6 \\
\hline toucher & 49.43 & 56.15 & 7 & 2 & 2 & 12 & 8 \\
\hline tripoter & 3.09 & 2.3 & 8 & 3 & 1 & 7 & 3 \\
\hline Mean & 6.27 & 9.75 & 7.67 & 2.42 & 1.08 & 6.33 & 4.17 \\
\hline SD & 13.72 & 15.39 & 2.10 & 0.51 & 0.29 & 2.53 & 2.52 \\
\hline \multicolumn{8}{|c|}{ Non-tactile verbs } \\
\hline blâmer & 4.37 & 2.03 & 6 & 2 & 1 & 6 & 2 \\
\hline défier & 3.92 & 4.39 & 6 & 2 & 1 & 5 & 6 \\
\hline délaisser & 0.28 & 1.01 & 9 & 3 & 1 & 1 & 2 \\
\hline disputer & 10.54 & 4.12 & 8 & 3 & 1 & 10 & 3 \\
\hline distraire & 7.56 & 13.38 & 9 & 2 & 1 & 1 & 2 \\
\hline héberger & 2.8 & 2.7 & 8 & 3 & 1 & 6 & 2 \\
\hline inciter & 2.01 & 2.43 & 7 & 3 & 1 & 5 & 3 \\
\hline méditer & 2.44 & 4.8 & 7 & 3 & 1 & 6 & 3 \\
\hline ménager & 1.73 & 8.45 & 7 & 3 & 3 & 9 & 4 \\
\hline négliger & 1.62 & 4.73 & 8 & 3 & 1 & 12 & 3 \\
\hline plaisanter & 6.24 & 6.01 & 10 & 3 & 1 & 3 & 2 \\
\hline présenter & 56.16 & 28.99 & 9 & 3 & 2 & 7 & 2 \\
\hline Mean & 8.31 & 6.92 & 7.83 & 2.75 & 1.25 & 5.92 & 2.83 \\
\hline SD & 15.35 & 7.70 & 1.27 & 0.45 & 0.62 & 3.34 & 1.19 \\
\hline \multicolumn{8}{|c|}{ Action verbs } \\
\hline amener & 35.6 & 18.18 & 6 & 3 & 1 & 6 & 1 \\
\hline arroser & 5.53 & 4.46 & 7 & 3 & 1 & 10 & 3 \\
\hline bâtir & 5.62 & 8.24 & 5 & 2 & 1 & 3 & 5 \\
\hline déchirer & 4.27 & 8.72 & 8 & 3 & 1 & 10 & 2 \\
\hline découper & 4.36 & 4.93 & 8 & 3 & 1 & 10 & 3 \\
\hline éplucher & 1.32 & 3.04 & 8 & 3 & 1 & 6 & 2 \\
\hline percer & 6.19 & 11.22 & 6 & 2 & 1 & 9 & 5 \\
\hline renverser & 7,00 & 7.64 & 9 & 3 & 1 & 10 & 2 \\
\hline scier & 1.12 & 2.43 & 5 & 1 & 1 & 8 & 4 \\
\hline tricoter & 1.37 & 3.11 & 8 & 3 & 1 & 6 & 3 \\
\hline verser & 4.62 & 9.86 & 6 & 2 & 1 & 10 & 5 \\
\hline visser & 1.45 & 0.88 & 6 & 2 & 1 & 10 & 6 \\
\hline
\end{tabular}




\begin{tabular}{|l|r|r|r|r|r|r|r|} 
Mean & $\mathbf{6 . 5 4}$ & $\mathbf{6 . 8 9}$ & $\mathbf{6 . 8 3}$ & $\mathbf{2 . 5 0}$ & $\mathbf{1 , 0 0}$ & $\mathbf{8 . 1 7}$ & $\mathbf{3 . 4 3}$ \\
\hline $\mathrm{SD}$ & 9.39 & 4.82 & 1.34 & 0.67 & 0,00 & 2.37 & 1.56 \\
\hline \multirow{3}{*}{ Statistics } & $\mathrm{F}(2,33)=$ & $\mathrm{F}(2,33)=$ & $\mathrm{F}(2,33)=$ & $\mathrm{F}(2,33)=$ & $\mathrm{F}(2,33)=$ & $\mathrm{F}(2,33)=$ & $\mathrm{F}(2,33)=$ \\
& .086, & .304, & 1.32, & 1.17, & 1.24, & 2.22, & 1.58, \\
& $p=.918$ & $p=.740$ & $p=.280$ & $p=.322$ & $p=.302$ & $p=.124$ & $p=.222$ \\
\hline
\end{tabular}


Table S3. Rating results for the somatosensory- and action-relatedness of tactile, non-tactile and action verbs used in Experiments 2 and 3. Ratings were performed on a 6-point scale from 0 to 5 (0: verb not related at all to any tactile sensation/action; $5=$ verb highly related to a tactile sensation/action). Rating 1 was done by 19 naïve French volunteers (different from participants of the three experiments). Ratings 2 and 3 were carried out by the participants at the end of Experiments 2 and 3, respectively. Means and Standard Deviations (SD) are reported for each verb list. In the three rating sessions, tactile verbs were significantly more associated with tactile sensation than action verbs (rating 1: $t=-13.15, p<.001$; rating 2: $t=-10.86, p<.001$; rating 3: $t=-13.48, p<.001$ ) and non-tactile verbs (rating $1: t=-23.87, p$ $<.001$; rating 2: $t=-18.31, p<.001$; rating $3: t=-21.28, p<.001)$. Action verbs also significantly evoked more tactile sensation that non-tactile verbs (rating 1: $t=-23.87, p<.001$; rating 2: $t=-7.45$, $\mathrm{p}<.001$; rating $3: t=-7.80, p<.001)$. As to action-relatedness, participants in the three ratings judged action verbs to be more associated with actions than tactile verbs (rating 1: $t=2.05, p=.11$; rating 2: $t$ $=3.32, p=.006$; rating $3: t=2.63, p=.033$ ) and non-tactile verbs (rating $1: t=-16.46, p<.001$; rating $2: t=-10.62, p<.001$; rating $3: t=-14.23, p<.001)$. Note that as expected, tactile verbs were also rated as more action-related than non-tactile verbs (rating 1: $t=-14.41, p<.001$; rating $2: t=-7.30, \mathrm{p}<.001$; rating 3: $t=-11.59, p<.001)$.

\begin{tabular}{|c|c|c|c|c|c|c|}
\hline & $\begin{array}{c}\text { Tactile } \\
\text { (rating1) }\end{array}$ & $\begin{array}{c}\text { Action } \\
\text { (rating1) }\end{array}$ & $\begin{array}{c}\text { Tactile } \\
\text { (rating2) }\end{array}$ & $\begin{array}{c}\text { Action } \\
\text { (rating2) }\end{array}$ & $\begin{array}{c}\text { Tactile } \\
\text { (rating3) }\end{array}$ & $\begin{array}{c}\text { Action } \\
\text { (rating3) }\end{array}$ \\
\hline \multicolumn{7}{|c|}{ Tactile Verbs } \\
\hline caresser & 4.58 & 4.21 & 4.67 & 3.29 & 4.58 & 3.79 \\
\hline chatouiller & 4.32 & 4.11 & 4.62 & 3.50 & 4.33 & 3.62 \\
\hline effleurer & 4.11 & 3.42 & 4.37 & 2.75 & 4.67 & 2.87 \\
\hline frôler & 3.21 & 2.95 & 3.87 & 2.67 & 4.25 & 2.62 \\
\hline frotter & 4.21 & 4.26 & 4.08 & 3.46 & 4.25 & 3.79 \\
\hline gratter & 4.37 & 4.47 & 4.17 & 3.58 & 4.42 & 3.67 \\
\hline grattouiller & 4.05 & 4.16 & 4.04 & 3.17 & 4.42 & 3.12 \\
\hline masser & 4.68 & 4.32 & 4.75 & 3.75 & 4.83 & 3.92 \\
\hline palper & 4.37 & 3.84 & 4.50 & 3.33 & 4.67 & 3.58 \\
\hline tâter & 4.32 & 3.79 & 3.96 & 2.67 & 4.25 & 3.29 \\
\hline toucher & 4.79 & 4.11 & 4.62 & 2.96 & 4.62 & 2.87 \\
\hline tripoter & 4.37 & 4.05 & 4.08 & 2.92 & 4.42 & 3.42 \\
\hline Mean & 4.28 & 3.97 & 4.31 & 3.17 & 4.48 & 3.38 \\
\hline SD & 0.40 & 0.43 & 0.31 & 0.37 & 0.19 & 0.42 \\
\hline \multicolumn{7}{|c|}{ Non-Tactile Verbs } \\
\hline blâmer & 0.11 & 2.16 & 0.29 & 2.04 & 0.62 & 1.59 \\
\hline défier & 0.05 & 1.68 & 0.54 & 2.46 & 0.25 & 1.79 \\
\hline délaisser & 0.11 & 1.74 & 0.62 & 1.83 & 0.50 & 1.67 \\
\hline disputer & 0.26 & 2.26 & 0.92 & 2.29 & 0.62 & 1.79 \\
\hline distraire & 0.05 & 2.05 & 1.29 & 2.46 & 1.00 & 1.75 \\
\hline héberger & 0.16 & 1.79 & 0.54 & 2.42 & 0.50 & 1.37 \\
\hline inciter & 0.32 & 1.89 & 0.58 & 2.17 & 0.46 & 1.42 \\
\hline méditer & 0.42 & 2.05 & 1.33 & 1.87 & 1.21 & 1.50 \\
\hline ménager & 0.42 & 1.47 & 0.83 & 1.71 & 0.79 & 1.24 \\
\hline négliger & 0.16 & 1.05 & 0.50 & 1.17 & 0.46 & 1.08 \\
\hline plaisanter & 0.32 & 1.79 & 0.96 & 2.62 & 0.58 & 2.04 \\
\hline présenter & 0.37 & 2.63 & 0.83 & 2.25 & 0.42 & 2.25 \\
\hline Mean & 0.22 & 1.88 & 0.77 & 2.11 & 0.62 & 1.62 \\
\hline SD & 0.14 & 0.40 & 0.32 & 0.41 & 0.27 & 0.33 \\
\hline on-Tact & Verb & & & & & \\
\hline
\end{tabular}




\begin{tabular}{|l|r|r|r|r|r|r|} 
amener & 1.00 & 4.16 & 1.12 & 3.54 & 1.04 & 3.75 \\
\hline arroser & 1.21 & 4.16 & 1.71 & 3.71 & 1.75 & 4.00 \\
\hline bâtir & 1.84 & 4.11 & 1.54 & 3.75 & 1.50 & 3.25 \\
\hline déchirer & 2.42 & 4.16 & 2.71 & 3.75 & 2.71 & 3.67 \\
\hline découper & 2.26 & 4.21 & 2.37 & 3.42 & 1.62 & 3.79 \\
\hline éplucher & 2.63 & 4.47 & 3.04 & 3.46 & 3.37 & 4.12 \\
\hline percer & 2.63 & 4.42 & 3.04 & 3.96 & 2.62 & 3.67 \\
\hline renverser & 1.95 & 4.05 & 1.96 & 3.54 & 1.92 & 3.08 \\
\hline scier & 2.68 & 4.58 & 2.75 & 4.21 & 2.42 & 4.33 \\
\hline tricoter & 2.32 & 4.05 & 3.00 & 3.21 & 2.50 & 4.12 \\
\hline verser & 1.32 & 4.32 & 1.46 & 3.46 & 1.21 & 3.83 \\
\hline visser & 2.26 & 4.58 & 1.83 & 3.83 & 1.71 & 3.75 \\
\hline Mean & $\mathbf{2 . 0 4}$ & $\mathbf{4 . 2 7}$ & $\mathbf{2 . 2 1}$ & $\mathbf{3 . 6 5}$ & $\mathbf{2 . 0 3}$ & $\mathbf{3 . 7 8}$ \\
\hline SD & 0.59 & 0.20 & 0.69 & 0.27 & 0.69 & 0.35 \\
\hline \multirow{2}{*}{ Statistics } & $\mathrm{F}(2,33)=$ & $\mathrm{F}(2,33)=$ & $\mathrm{F}(2,33)=$ & $\mathrm{F}(2,33)=$ & $\mathrm{F}(2,33)=$ & $\mathrm{F}(2,33)=$ \\
& $p<.001$ & $p<.001$ & $p<.001$ & $p<.001$ & $p<.001$ & $p<.001$ \\
\hline
\end{tabular}

